\title{
The performance of truth: politicians, fact-checking journalism, and the struggle to tackle COVID-19 misinformation
}

\author{
María Luengo $^{1}$ - David García-Marín ${ }^{1}$
}

Published online: 28 September 2020

(c) Springer Nature Limited 2020

\begin{abstract}
Since the World Health Organization (WHO, February 2, 2020) reported that the spread of coronavirus disease has been accompanied by a "massive infodemic," the COVID-19 outbreak has become a national and international battleground of a struggle against misinformation. Fact-checking outlets around the world have been actively counteracting false and misleading information surrounding the pandemic. In this article, we conceptualize fact checkers in terms of the "interpretative power" that journalism holds in processes of political performances (Alexander in Soc Theory 22(4): 527-573, 2004, in: The performance of politics. Obama's victory and the struggle for democratic power. Oxford University Press, Oxford/New York, 2010). Drawing on virus-related fact checks from Poynter's International Fact-Checking Network (IFCN) database, we make two arguments. First, we argue that the new phenomenon of specialized "fact checking" might be considered as a further explicitly differentiated element of Alexander's model of cultural performance, which fulfills a double duty: trying to contribute to further "de-fusion" (separating audiences from actors when the latter lack authenticity and credibility) on the one hand, and working to overcome it on the other. Second, we explain how new fact-checking practices have become a reflexive supplement to the news media of the civil sphere that might be able to help the civil sphere's communicative institutions to defend truthfulness in a manner that contributes to democracy.
\end{abstract}

Keywords Covid-19 · Misinformation · Journalism · Fact checkers · Performance · Civil sphere

María Luengo

maria.luengo@uc3m.es

David García-Marín

dgmarin@hum.uc3m.es

1 Department of Communication, Carlos III University, 133, Getafe, 28903 Madrid, Spain 
Since the World Health Organization (WHO, February 2, 2020) reported that the spread of coronavirus disease has been accompanied by a "massive infodemic," the COVID-19 outbreak has become a national and international battleground of a struggle against misinformation. Fact-checking outlets around the world-including independent media and fact checkers; public and civil entities; social media platforms; and tech giants such as Facebook, Google, Twitter, and YouTube-have been actively counteracting false and misleading information surrounding the pandemic. Independent journalism has been at the core of this common action of battling misinformation. According to a study published in April 2020 by the Reuters Institute for the Study of Journalism (hereafter RISJ) and the Oxford Internet Institute, the number of independent fact checkers increased dramatically between January and March 2020. Findings in this study show that the number of English-language fact checks produced by independent media and fact checkers rose more than 900 percent in these months. The false narratives about COVID-19 that have been identified have been of a dynamic and changing nature, adapting to the social and informative context and becoming increasingly politicized (García-Marín 2020). While misinformation about scientific issues (especially that related to the origin of the virus) was the focus of the most prominent false narrative at the beginning of the crisis, fake news on political and institutional measures became more relevant as the pandemic advanced. Fact checking's impressive growth has occurred in parallel with record-breaking months for news traffic and media subscriptions, even if print and online newspapers have continued to face dramatic losses in advertising revenues (Cerezo 2020; Financial Times, May 29, 2020; El Confidencial, April 20, 2020). Interestingly, journalism's fight against misinformation has taken place in a context in which the news seems to connect with ordinary citizens more broadly, lessening inequalities between media audiences (Casero-Ripollés 2020).

In its communicative dimension, the COVID-19 outbreak has confirmed citizens' search for trustworthy and reliable information, increasing opportunities for professional journalism to gain cultural and social ground. This cultural work is rooted in core values of journalism that frame social events and actors within the broader discourse of civil societies (Alexander 2006, 2010; Alexander et al. 2016). In confronting the threat of COVID-19 mis- and disinformation, journalists have coded public claims within the civil binary of truthfulness versus falsehood. This binary also reflects the dividing line between sacred facts and mundane opinion, particularly in the cultural context of North American journalism. The cultural struggle over the meaning of "truth" not only positions professional journalism strongly within society but also "cuts to the very core of the journalistic gaze's ability to hold power to account," as Kreiss has put it (2019, p. 29).

In this article, we conceptualize fact checkers in terms of the "interpretative power" (Alexander 2004) that journalism holds in processes of political performances (Alexander 2010). We do so based on a cultural-sociological perspective and on civil sphere theory. Our aim is to shed light on both this new phenomenon of fact checkers and the increasing thematization of misinformation and "false facts," which the COVID-19 crisis has intensified. In particular, we focus on the impact of fact-checking journalism on alleged false claims from politicians and public authorities at peak times of the pandemic. Drawing on virus-related fact checks 
from Poynter's International Fact-Checking Network (IFCN) database, ${ }^{1}$ we looked at fact checks published between January 22, 2020, the date when COVID-19 misinformation started, and May 20, by which time the coronavirus had spread around the globe. The selected period included a wide range of fact checks based on turning points of political performances related to the coronavirus outbreak. We focused on fact checks produced by the Spanish and North American fact-checking organizations. In the IFCN database, the US and Spain, along with India, represent the countries with the highest fact-checking activity during the research period. Beyond quantitative criteria, both countries serve as paradigmatic examples of political polarization that the pandemic has not only unveiled but also aggravated. As we will observe later, according to Alexander's theory of social performance (2004), a context of social and political fragmentation poses a great challenge to political actors when they attempt to connect with audiences. After applying filtering to remove fact checks that did not relate to political performances and eliminating repeated reports, the final sample consisted of 162 checks.

In our approach to fact checkers, we make two arguments. First, we argue that the new phenomenon of specialized "fact checking" might be considered as a further explicitly differentiated element of Alexander's model of cultural performance, which fulfills a double duty: trying to contribute to further "de-fusion" (separating audiences from actors when the latter lack authenticity and credibility) on the one hand, and working to overcome it on the other. Second, we explain how new fact-checking practices have become a reflexive supplement to the news media of the civil sphere - a kind of empirical response - that might be able to help the civil sphere's communicative institutions to defend truthfulness in a manner that contributes to democracy.

Where are independent fact checkers located within Alexander's model of cultural performance? How, within this model, do fact checkers work in political processes of de- and re-fusion? To what extent and under what terms do fact checkers explain their own activity of holding power to account when assessing the veracity of politicians' words and actions? These were the principal questions that we asked as we began to work with our sample of fact checks, though as will be seen, our analysis ultimately yielded findings that go beyond them. We answered them by conceptually placing fact checkers within the interpretative power of the civil sphere and analytically presenting fact checkers' democratic role in terms of Alexander's cultural pragmatics.

To ascertain based on Alexander's model how fact checkers work in political processes of de- and re-fusion, we tracked fact-checking narratives surrounding COVID-19 misinformation using the data set described above. We explore two types of misinformation claims evaluated by fact checkers: (1) bottomup false claims about government responses to the pandemic; (2) top-down

\footnotetext{
1 Poynter's IFCN currently brings together fact checkers from 70 countries. It represents the largest international fact-checking project at the moment. Although European, Asian, and American entities have a higher prevalence within the IFCN, fact-checking organizations from all continents ensure the global scope of the network.
} 
misinformation emanating from public authorities (leading politicians, governments, etc.).

There are several reasons behind our choice to focus on these two types of false or misleading claims. First, although misinformation surrounding COVID19 has come in many varieties - from conspiracy theories and claims that inflate or downplay the numbers of coronavirus cases to fake cures and tests-much COVID-19 misinformation concerns the actions of public authorities and politicians (RISJ Factsheet, April 2020). To the extent that these claims often involve prominent public figures, they become, in turn, stimuli for public engagement and viral content to be disseminated quickly throughout social media. Second, as the RISJ factsheet shows, "False information spread by politicians, celebrities, and other prominent public figures" accounted for 69 percent of total engagement on social media, though their claims made up just 20 percent of those identified in the study. Finally, the preliminary data that we collected confirmed the significant extent to which these two types of misinformation claims have proliferated and spread. This confirmation prompted us to focus our analysis on factchecking activity undertaken in relation to politicized misinformation concerning COVID-19.

We also revisited the data set of fact checks described above, shifting our focus from the political actors to the fact checkers themselves. In doing so, we deploy the analytical category of "metajournalistic discourse" (Carlson 2015) to evaluate fact checkers' self-reflection about the authority and legitimacy of their activity.

Overall, our answers to the questions that we posed aim to cross-examine how a core function of professional journalism and, particularly, of fact-checking journalism-that of watchdog-has acquired new significance in the domain of political performances in times of crisis and social polarization.

\section{Fact checkers as an extension of professional-accountability journalism}

The rise of fact checkers evidences the widely documented analytical turn adopted by journalism institutions from the second half of the 20th century. By the 1960s, American journalism took a more skeptical and critical stance toward political power (Downie and Schudson 2009; Schudson 1978). One of the main causes of this shift was the adoption of more sophisticated methodologies and perspectives from social sciences that proliferated within the field of journalism studies in US universities (Graves 2016). Likewise, the increase in the resources available for research in newsrooms (access to official documents and specialized bibliography) gave journalists greater possibilities for engaging with output from scientific disciplines, in order to produce more in-depth, comprehensive, and critical reporting. This shift in journalism culture was driven by a greater demand from the public for critical content vis-à-vis political and economic elites. It was also professionally motivated by journalists' aspirational desire for authority and legitimacy in the public sphere. As Graves (2016, p. 65) observes, 
Analytical reporting allows more play for reporters' political, intellectual, and literary ambitions. It gives rise to areas of specialized expertise and training that help to legitimate reporters' claims to be news "professionals"-areas such as "precision journalism" in the 1970s or "data journalism" today. And it simultaneously fulfills and celebrates journalism's mission as a democratic watchdog, elevating the reporter vis-a-vis the public figures she reports on.

Reporting that seeks to check political claims has been present in American journalism since the mid-twentieth century in the form of op-ed pages, investigative journalism, and the alternative press. However, in the 1980s, journalists in the US started to argue that objective reporting had served as a vector that uncritically spread the falsehoods that politicians consciously conveyed to the public. American journalists thus "became more comfortable attaching doubt to political claims in the news," as Graves (2016, p. 56) points out. In the 1992 presidential election, more than half of the major US newspapers published at least one report focused on verifying campaign messages, a trend that spread to the local media in the following years.

In North America, fact checkers initially originated from nonprofessional civil initiatives such as Snopes. Founded in 1995, it was the first website entirely specialized in fact checking. FactCheck.org was launched in 2003, while Poynter's PolitiFact and the Washington Post's Fact Checker were created shortly thereafter in response to the 2004 presidential campaign, which was characterized by the candidates' rampant use of falsehoods. Fact checkers at first operated during national election campaigns. They achieved a widespread presence in legacy news media organizations, which incorporated sections specifically dedicated to verifying the candidates' claims.

Interestingly, the fact-checking movement in the United States has been accompanied by numerous conferences and summits that have brought together different institutions within the field. In November 2007, one of the first meetings was celebrated in Washington, under the title "Pants of Fire: Political Mendacity and The Rise of Media Fact-Checkers." Following this event, from 2011 to 2015, several national and international conferences were held in various American cities (New York, Austin, Cambridge, and Washington). Journalists and experts gathered to discuss fake news, the future of fact checking, and the movement's increasingly global scope, among other issues. In the context of COVID-19, the most active American fact checkers so far have been PolitiFact, LeadStories, AFP, Science Feedback, and FactCheck.org, all of which are members of the International Fact-Checking Network (IFCN).

In Spain, fact checking institutions emerged in 2006. The first one was Miniver, an independent project launched by the journalist Alfredo Expósito. Miniver has no connection to any political party or media group. Since then, different entities with varying degrees of success have arisen. Some are independent-for example, Maldita, which was founded in 2013, and Newtral, which was founded in 2018. Others are linked to existing news media organizations. La Chistera (2015) is owned by the digital newspaper El Confidencial. Verdad o Mentira (2016) is part of Periodista Digital, also a digital newspaper. El Cazabulos (2017) is run by eldiario.es. 
And EFE Verifica (2019) is linked to EFE, the state news agency. These predominantly digital projects are often characterized by their use of their founders' brand as a promotion strategy (Manfredi 2015). As we observed in the American case, some of these initiatives are a regular presence in national media, especially in electoral periods, and so have achieved widespread visibility. The main difference between the Spanish context and the American one is the absence of relevant national events that contribute to building a movement or community with deep interactions and knowledge exchange among the different projects and actors. Currently, Maldita, Newtral, and EFE Verifica, which belong to the IFCN, are the most active Spanish fact checkers.

At the global level, the greatest growth in the number of fact-checking initiatives took place between 2012 and 2017 (Vázquez-Herrero et al. 2019). In November 2016, Facebook confronted accusations of having promoted the spread of fake news in the US presidential election held months earlier. The social network signed an agreement with several fact checkers from different countries, including the US and Spain, to detect and label false content circulating on Facebook. The event helped to boost fact checkers' fight against false information internationally. One year before, in 2015, Poynter's IFCN was created to bring together fact checkers worldwide under the label of "trust, transparency and accountability journalism" (Poynter 2020). The IFCN analyzes formats and trends in fact-checking practice around the world, promotes common basic standards through a code of principles, monitors the impact of fact-checking activity, convenes fact checkers in a yearly conference, and promotes collaborative efforts in international fact checking (Poynter 2020).

Fact-checking websites verify news stories once they have been published by the media and/or been disseminated by users of social networks (Mantzarlis 2018). Fact checks tend to focus on news stories pertaining to national issues. They are structured and presented in a very similar way to traditional journalism pieces that address a specific question, explain data, or assess specific claims. Fact checks integrate original sources and, according to Vázquez-Herrero et al. (2019, p. 4), "stand out for the richness and diversity in the use of verification mechanisms." Fact checkers' practices differs from the journalistic routines of other media organizations. Fact-checking stories do not usually set the agenda or reveal new facts. They are limited to verifying stories that have already been published. They therefore correspond to a reactive dynamic: checks are always reactions to what others have said or done.

In its current form, fact-checking journalism basically consists in scrutinizing data gathered or produced by others (for example, sourcing, verifying, and scrutinizing claims, utterances, and data). Fact checkers do not generate data or perform any of the news-gathering activities that are a central part of news journalists' workfor example, identifying events of public interest, seeking comment from the people involved in those events, and gathering data from various sources to create factual accounts of them. Fact-checking journalists are supposed to have the skills required to work with specialized tools-for example, geo-location tools and software that detects manipulated videos. Unlike journalists at legacy and new media organization, fact checkers do not have an explicit editorial line. This does not make them immune to bias, however. On the contrary, they have been accused of it on many 
occasions. That said, they apply a different editorial culture to the types of claims they usually label as false. When this approach to fact checking is used by legacy media, it is always presented as a specialized practice. Legacy media outlets make most use of it in electoral campaign periods to debunk politicians' false claims or during crises such as the COVID-19 pandemic.

\section{Fact-checking journalism's interpretive power within scenarios of false information}

The activities of independent fact-checking websites became professionalized very recently. They seem to have done so particularly from 2016, when the political campaigns that ended in victory for Donald Trump in the United States and for Brexit in the United Kingdom arguably served as catalysts for the disinformation phenomenon (McIntyre 2018). That year, the Oxford Dictionary (2016) included the term post-truth, which the dictionary named as its word of the year. In a post-truth discursive context in which the importance of facts and scientific evidence is diminished to assert ideological positions, fact checkers have in our view become a new extension of independent fact-checking and accountability journalism. Fact checkers' work focuses on socially contentious, polarizing issues and is grounded in the use of digital-media technologies. From a performative perspective, we understand this professional extension of journalism into fact checking as a further distinguishing aspect of journalism's unique "interpretive power" (Alexander 2004, 2010). Among Alexander's elements of performance (2004), "social power" is divided into "material power" and "interpretive power." Alexander locates news media within the latter. By applying his model to political representation and, specifically, to the case of the Obama campaign in the US presidential elections of 2008, Alexander documents - from a sociological point of view - the professional differentiation of journalism. Alexander also looked even further back in time to track the evolution of journalism from the origins of the partisan press to a progressive "media reflexivity" (Alexander 2010, p. 290) that served as a vehicle for the interpretive power of contemporary independent journalism.

Journalism carries out a reflexive mediation between political power and citizens, intervening specifically in performative processes in which politicians try to bond with audiences. It is an interpretive power that now also takes the form of independent fact checkers, whose verifications are also made public by the media.

As extensions of the civil sphere's interpretive institutions, fact checkers contribute to activating the symbolic codes that guide the discourse and action of political elites toward civil or, on the contrary, anti-civil spheres. They evaluate what citizens should consider acceptable in democratic life. Their legitimacy to play this role is based on the presentation of facts, expert knowledge, and reason-driven reporting. This function entails countless difficulties owing to the current context of disinformation and fake news. Although these phenomena have multi-dimensional roots (European Commission 2019; Aparici and García-Marín 2019), several scholars locate an essential part of the disinformation problem in the new sociotechnical reality derived from the digitalization of information (Han 2017; Lanier 
2018; McIntyre 2018; Pariser 2011; D’Ancona 2017; Bartlett 2018; Berinsky 2015). These scholars argue that a set of social and psychological factors leads subjects to believe and share false information. Fiske and Taylor (2013, p. 54) have argued that, in addition to the processes of cognitive dissonance (Festinger et al. 1956) and confirmation biases, "the audience's cognitive misery prevents the public from making significant efforts to understand and interpret the information they consider non-essential." Individuals instead take mental shortcuts that are based on previous beliefs and experiences. These limitations add to the impact of feelings and emotions, especially when it comes to audience engagement with online information. It has been proven that emotional information is more attractive (Reis et al., 2015) and more rapidly shared on social networks (Zillmann 2009). Likewise, audiences find social gratification in disseminating breaking news, even if what they are sharing is inaccurate. Sharing information provides the subject with a sense of belonging to a community through his or her interacting collectively with the same stories with which a social group is engaged (Hoffner et al. 2009). On social networks, both the amount of information shared and the speed with which it is shared (regardless of its veracity) give the user prestige and status (Bowman and Cohen 2020).

Beyond the above psychological and social factors, the current digital scenario of mis- and disinformation reveals the cultural dynamics of fragmentation and polarization that characterize our civil spheres (Alexander et al. 2019). For authors such as Kreiss (2017), these dynamics reflect partisanship in which particularistic identities diminish civil evaluation to a degree that critically undermines the functioning of the communicative and regulatory institutions of the civil sphere.

\section{How fact checkers work in performative processes of de- and re-fusion: the case of COVID-19 misinformation}

The devaluation of facts in the name of partisan interests might seem particularly critical in the context of the global crisis caused by the novel coronavirus. Based on a cultural performance framework (Alexander 2004), our research seeks to analyze fact checkers' contribution to the civil sphere's discourse of truth in the context of the spread of misinformation during the pandemic. We analytically locate the journalism activity of fact checking within today's complex performative processes of de-fusion/re-fusion. According to cultural sociologist Jeffrey Alexander (2004, 2010), these processes characterize the democratic struggle for power within our polarized and fragmented democracies. Alexander observes that as societies become more complex and segmented, the elements of social performance remain de-fused or separated from one another. To be effective, performances must engage in a project of re-fusion. As Alexander (2004, p. 529) puts it,

To the degree they achieve re-fusion, social performances become convincing and effective-more ritual-like. To the degree they remain de-fused, they seem artificial and contrived.... Failed performances are those in which the actor, whether individual or collective, has been unable to sew back together the elements of performance to make them seem connected seamlessly. 
As specialized and differentiated "interpretive powers," journalists and, particularly, new independent fact checkers can be analytically understood within these performative processes of de-fusion/re-fusion. Their evaluations make it possible to prevent actors from connecting with audiences or, at the very least, facilitating re-fusion.

In the specific scenario of the novel coronavirus crisis, political leaders' and governments' authenticity has been challenged at a time when they have had to appear in an unprecedented number of press conferences, national addresses, and so forth. When operating before the wider public, political actors have needed to combine accurate information with persuasive messages aimed at involving people in tackling the spread of the virus (Canel 2020). In a context of social polarization, misinformation flows that directly question the words and actions and the overall legitimacy of public authorities become potent tools for preventing governments from re-fusing with audiences. Nevertheless, attempts to scrutinize potential misinformation could be viewed with suspicion when they are undertaken by the public authorities themselves. ${ }^{2}$ As Brennen et al. ask in the RISJ study (April 7, 2020), "How many people will accept as credible a government trying to debunk or refute misinformation that casts that very same government in a negative light?" Their answer is that "independent fact checkers can provide authoritative analysis of misinformation while helping platforms identify misleading and problematic content, just as independent news media can report credibly on how governments and others are responding (with varying degrees of success) to the pandemic."

We analyze pieces of fact checking vis-à-vis the basic true/false dichotomy and, more importantly, vis-à-vis the gradations between these two extremes devised by each fact-checking service-for example, American fact checker PolitiFact deploys a "Truth-o-Meter" that comprises the categories "True," "Mostly True," "Half True," "Mostly False," and "Pants on Fire." By using such categorizations, these institutions break the true/false dichotomy, incorporating intermediate labels between truth and lie. On the other hand, there are fact checkers that do not use labels, such as EFE Verifica (Spain); its activity is focused on explaining fact checking, so citizens must reflect on the claim's degree of "truth."

In our exploration, we examined the sampled items and their checks of "facts" (or "false facts") to ascertain their symbolic dimension, in which "true" and "false," beyond referring to an empirical reality, indicate the degree of plausibility and authenticity of the person who made the claim subject to fact checking. Specifically, three blocks of categories guided our analysis of each report from our sample. After identifying a claim, we first analyzed its content based on narrative keys - that is, we examined the event or act described, its protagonists, and its spatial and temporal context. Second, we looked at the content of the fact check to capture interpretative, contextual, and in-depth elements.

\footnotetext{
2 An example here is the case of the public outcry in Spain when radio channel Cadena SER disclosed an email sent to the national Civil Guard headquarters urging it to identify fake news "likely to cause social stress and discontent toward government institutions" (Cadena SER, April 20, 2020). Previously, José Manuel Santiago, a Spanish Civil Guard officer, had pointed out at a press conference that this institution was working to prevent the damage caused by hoaxes on social networks and, consequently, to minimize the anti-government climate of opinion.
} 
Third, we examined "metajournalistic discourse" (Carlson 2015): what the verifiers say about themselves, the verification process that they carried out, and the way in which the fact-checking institution itself appears in the content of its own verification.

As we said before, we focus on two types of political fact checking: bottom-up stories produced and spread by ordinary citizens or partisan websites; and top-down stories generated by the acts of high-level politicians, celebrities, or other prominent public figures (Brennen et al. 2020). Both types of political fact checking are correlated with two performative patterns:

Bottom up This is based on official denials (institution driven) and, to a lesser extent, on forensic analysis of disinformation material (analysis of videos and pictures in search of possible manipulative editing and the examination of such material to uncover false contextualization), as well as on extensive investigation of disinformation sources. Fact checkers thus assume the "metaphor of the court," where the politicians accused of disinformation have the possibility of explaining the veracity of the/their facts. Under this performative pattern, fact checkers take on a passive role, configuring themselves as a cultural space in which the truth emerges, brought to light by its protagonists. The most frequent falsehoods that could be labeled as "bottom up" are user-created hoaxes spread on social networks, such as the story affirming that students from Madrid would have to attend class in summer due to the coronavirus crisis. This story, denied by the Madrid government and reported by Maldita.es on March 10, was based on an anonymously fabricated false document that aimed to imitate an official document.

Top down This is grounded in active research processes consisting in the review of external sources (including traditional media), the analysis of official data, and, above all, consultation with experts (data/science driven), which leads to more extensive research and greater resource mobilization. According to this pattern, the fact checkers' work is guided by the logic of demonstration. It is an explanatory performance, in which fact checkers take on the role of a researcher who, like scientists in their laboratories, develops complex strategies to prove or refute hypotheses in an active search for the truth. The top-down denials are usually pieces of information selected-far from the audiences' propositional actions - according to the criteria of originality, relevance, and ideological balance (Graves 2016). We found that citizens rarely ask fact checkers to verify claims made by public figures. Instead, their attention focuses on the hoaxes generated by other individuals, which usually reach them horizontally, through instant messaging services such as WhatsApp. Donald Trump's claim about the poor quality of the tests provided by the WHO is an example of top-down narrative. This statement was rated as "False" by PolitiFact on March 17, using a total of six different sources, including health institutions, other media outlets, and scientific journals.

On the basis of these two types of claims, our hypothesis on how fact checkers contribute to de-fusion/re-fusion processes can be formulated as follows. If topdown claims are thematized as "false," then fact checkers contribute to de-fusion, as politicians are perceived as deceitful, secretive, or self-interested when it comes to their handling of the coronavirus crisis. By contrast, if top-down claims happen to be true, fact checkers help to overcome de-fusion. This logic changes in bottom-up claims on governments and politicians. If they are thematized as "false," then fact checking is helping to connect society with politicians, but if these claims are "true," a process of de-fusion is set in motion (Fig. 1). 


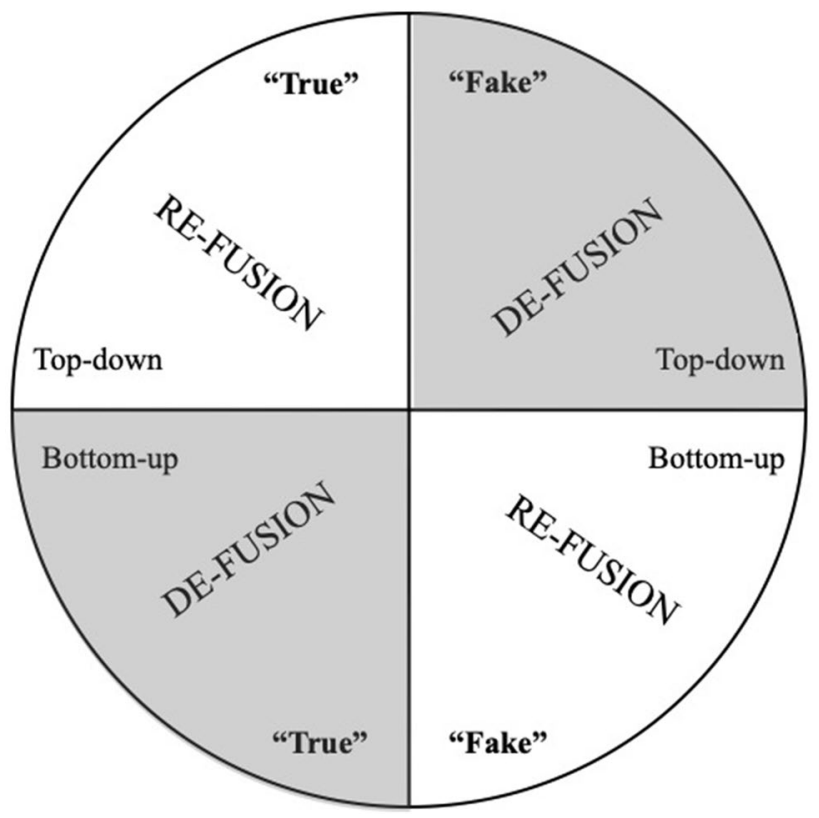

Fig. 1 Fact checkers' contribution to performative processes of de- and re-fusion

Despite their differences, both performative models (top down and bottom up) reveal that they entail complex tasks in which technology plays a subordinate role. Most of the checks are linked to expert consultation, review and analysis of official documents, and interpretation of data. In short, actions in which technological resources assume a secondary function normally involve data visualization or reverse image searches to detect videos and pictures taken out of context. On many occasions, fact checkers are simply a transmitter of the denial from the institution or the politician subject to allegations; in such situations, their role is closer to that of simple spokesperson of the institution, and they do not take any investigative action. This is the case in most of the Spanish fact checks analyzed. Thus, a double dimension is established in the performance of fact checking: "soft" fact checking (based on communicating the denial) and "hard" fact checking (exhaustive research and documentation for demonstrative and explanatory purposes). Soft fact checking is prominent, above all, in bottom-up verifications (usually generated by users on social networks, by partisan digital media, and by websites that create hoaxes). It involves documents that incorporate logos or identifying elements of public institutions to spread false measures. The document's authenticity and the information contained in it are then denied by the institution concerned. In this case, fact checkers simply report the denial, without any investigation or recourse to external experts. When research is undertaken, it is limited to checking whether the name of 
the impersonated institution is correct or elucidating some key aspects of a picture's editing that betrays the deception. Hard fact checking is connected to much more elaborate research methods where the analysis of different types of sources (institutional and journalistic) and consultation with experts constitute the raw material for reports that explain the reasons behind fact checkers' evaluations. The previously mentioned reports about Trump and Biden are representative examples of hard fact checking. In what follows, we first interpret fact checkers' responses to the performances of politicians and public authorities and then we examine fact checkers' selfreflective claims.

\section{Possibilities of re-fusion: overcoming political partisanship}

Contrary to arguments about diminishing of civil evaluation (Kreiss 2017) and the fragmentation of public opinion (Waisbord 2018) that make fact-checking journalism inoperative, we observed a veiled partisan fight that does not reach the levels of polarization that are specific to electoral contexts. In the Spanish case, there is a symbolic partisanship, building up from a political discourse that feeds on specific frameworks that favor one's ideological position when condemning the opposite stance. Fact-checking reports reflect a post-truth narrative. However, that narrative does not reach the level of aggressiveness and political radicalization of the political campaigns examined by Kreiss (2017). For example, when the president of the Community of Madrid, Isabel Díaz Ayuso, from the conservative Partido Popular (PP), indicated (falsely) that Madrid had met the requirements to open establishments and resume commercial activity after the hardest phase of the coronavirus crisis had passed, ${ }^{3}$ fact checkers echoed public discourses in Spain that associated Madrid's regional government with values such as freedom and economic openness. Conversely, these discourses link the current left-wing national government coalition with nationwide captivity and confinement. Public protests against the government called by the far-right VOX were also based on this pairing of opposite meanings (confinement versus freedom), and not on other types of values related to a crisis in public health and citizen security.

Fact checkers overcome these attempts to privilege political action aimed at demonizing institutions governed by the opposing political party. In the period covered by our data set, they symbolically located various regional and local administrations beyond the logic of confrontation, highlighting the values of collaboration, unity, and inclusion. In the case of Spain, fact checkers contributed to the process of re-fusion by leaving most of Spain's regions out of the particularistic political battle between Madrid and the central government. Fact checkers helped to balance this specific confrontation by revealing falsehoods about the numbers of infections and deaths. One of the main discourses surrounding the

\footnotetext{
3 The Spanish fact checker Newtral denied Ayuso's claim on May 14, 2020, stating that "the data do not prove her right: although the number of daily cases is increasing more slowly than the national average, the statistic that the president seems to be referring to is not the criterion assessed by the ministry to authorize a change in phase."
} 
coronavirus pandemic from the major opposition party in Spain, the center-right $\mathrm{PP}$, was based on the contrast between the supposed successful management of the regions governed by this political force and the national government's supposedly defective response to the virus. The latter part of this interpretation was debunked on several occasions by Newtral. For example, on May 19, 2020, this fact checker demonstrated that the PP's claim that Spain was at that time the country with the greatest increase in the number of deaths with respect to the previous year's data was completely false:

The claim is FALSE. According to the latest figures from EuroMOMO, which analyzes excess deaths, Spain recorded the third-lowest rate among the 24 countries and territories included, and in the last three weeks England, Italy, Belgium, Holland, and Sweden recorded a higher level of excess deaths.

By contrast, representatives of the same party claimed that the Community of Madrid-governed by the PP — was below the Spanish average for the number of infected people. In the same manner, Newtral (May 14, 2020) revealed that this statement was inaccurate: "The claim is MISLEADING. The Community of Madrid recorded a rate of 36.9 cases per 100,000 people, in contrast to the national average of 20."

The political struggle between Madrid and the Spanish government has been accompanied by another dispute between the so-called Spanish "historic nationalities"-territories with a long history of nationalist and independence movements such as Catalonia and the Basque Country - and the national institutions. This aspect came to light when the president of a Catalan business group (falsely) accused the Spanish army of requisitioning health equipment to protect against the coronavirus in Catalonia, information that was categorically denied by the Ministry of Defense, Newtral reported on March 18, 2020:

On March 17, the president of the Barcelona Chamber of Commerce, Joan Canadel, published a message on Twitter in which he accused the army of "requisitioning protection equipment against the coronavirus in Catalonia." The Ministry of Defense has told Newtral.es that this claim is "totally false."

Over in the United States, the same action of re-fusion within a symbolic scenario of division between the central government and states and between Republicans and Democrats is reflected in different verifications of false claims. These claims involve a partisan use of false data or facts, and they either were issued by the Trump administration as statements by the president himself or were allegedly said by Trump's Democratic opponents such as former vice president Joe Biden. On March 16, 2020, PolitiFact checked Joe Biden's claim that the Trump administration had rejected WHO coronavirus test kits. In a CNN Democratic presidential debate involving the two leading candidates for the Democratic nomination, Joe Biden and Vermont senator Bernie Sanders, Biden had said, "The World Health Organization offered the testing kits that they have available and to give it to us now. We refused them. We did not want to buy them." After a thorough 
investigation that used more than twenty sources, included the WHO itself, the US Food and Drug Administration, and email exchanges between different US officials and legacy and new media, PolitiFact reporters John Greenberg and Victoria Knight assessed Biden's assertion as "Mostly False." The fact checkers contextualized Biden's claim within a narrative of criticism on the Trump administration's response to the pandemic and rebutted the inaccurate information that Biden used to support his claim through data, facts, and detailed explanations pertaining to why the WHO never offered to sell test kits to the United States. The country had decided to develop its own protocols and coronavirus tests, just as other countries with strong health systems had done. This check reaffirmed that the American government had acted appropriately. It also tempered the criticism of the Democratic opponent, which was spurred by partisanship in the context of a political debate.

Conversely, fact checkers function as catalysts for de-fusion between politicians and citizens by refuting politicians' statements and by making public their lack of collaboration with fact-checking institutions. On a regular basis, these entities request information on the sources that politicians use to make certain statements labelled as false. The usual absence of explanations, which can be interpreted as an attitude contrary to transparency, constitutes a clear anti-civil value activated by political elites within the civil sphere. For instance, the Spanish fact checker Newtral investigated a claim by the VOX leader Santiago Abascal affirming the Hungarian government had distributed masks to the entire population, in contrast to the lack of similar measures from the Spanish authorities. After the Hungarian government confirmed that this information was false, Newtral (April 28, 2020) did not obtain any response from VOX when it consulted the party about the source used to make the statement: "Newtral.es contacted VOX's press team to find out the source of this information, but we have not yet received a response."

References to the lack of transparency of the Trump administration are constant in PolitiFact's checks. In a fact-checking story published on April 23, 2020, PolitiFact reporter Jon Greenberg evaluates as "mostly false" a statement made by Trump ("Hundreds and hundreds of labs are ready, willing, and able") during a press briefing on April 20, 2020. Trump additionally stated that the White House had a list that showed "many untapped labs are ready to go to do more testing." Describing the process of his investigation, Greenberg says:

We asked the White House for the data to back up Trump's assertion about hundreds of labs, but the press office declined to comment and did not provide the list Trump referenced. A spokesperson for the Health and Human Services Department said it couldn't provide a tally of these untapped labs.

Fact checkers' work proved effective in transforming the rhetorical performance of certain politicians in Spain. After the intense activity undertaken and the leading role achieved by national verifiers such as Newtral or Maldita, political elites began to construct discourses "in the name of truth." This was the case of the PP spokesperson in the Congress of Deputies, Cayetana Álvarez de Toledo, who shared via Twitter a video defending the investment in health made in the Community of Madrid (which is frequently criticized by left-wing parties owing to the constant cuts made to its health 
budget in recent years) and positioning herself "against hoaxes, and in favor of data" (Newtral, April 9, 2020). In the same context and on the same issue, this politician stated in a radio interview that her speech was based on true facts ("Let's go to the facts, which is the place where we can meet," she said). According to fact checkers, she lied on both occasions. The fact-checking entities' acts thus had a performative effect on the construction of political narratives in critical phases of the pandemic in Spain.

On other occasions, fact checks have a more profound effect and lead the disinformation's authors to amend their claims. This is the case of the Spanish conservative politician Rafael Hernando. On his Twitter account he shared a video in which a group of Muslims was seen participating in a protest. The video was taken out of context; the footage had been recorded before the COVID-19 outbreak. The politician used this material to criticize the government for these rallies, claiming that "if you are Catholic you cannot go to church and Easter is banned." The story was proven false by Newtral on April 27, 2020. After Newtral's verification, Hernando issued the following rectification on Twitter:

I have been told that this video is not from now but from a while ago. So, and because I'm not like the people in government, who never apologize when they make a mistake, even if their errors cause thousands of deaths, I do say sorry, and I apologize to Marlaska and the Muslim community. (Rafael Hernando on Twitter, April 27, 2020.)

Particularly in the case of US fact checkers such as PolitiFact, checks are carried out at the same time as political performances take place and, at most, within a period of 3 days after the claim has been made. In critical times such as the coronavirus crisis, in which politicians have had to appear on the public stage almost daily, the quick response of fact checkers runs parallel to and even anticipates the contingency of the actions and declarations of politicians. Their work therefore intervenes in the course of the politicians' subsequent performances. The aforementioned case of Cayetana Álvarez de Toledo's reaction to fact checking on her Twitter account (Newtral, April $9,2020)$ is an example of this. There are also paradigmatic examples of such reactions in the United States. On March 30, PolitiFact verified a false claim by Trump in which the president denied having criticized some states' governors for making unjustified requests for respirators. That statement was made in an interview with Fox News. The PolitiFact story describes a PBS journalist asking Trump if it was true that he had made such a claim about the governors. Trump replied that it was not true. It could be said that, at this point, PolitiFact's journalists symbolically entered the scene to verify who was telling the truth: the journalist or the president. After a thorough analysis of the case, the fact checker concluded that Trump had brazenly lied shamelessly; the site gave his claim a Pants on Fire rating.

\section{Where the public stands: digital platforms and legacy media as symbolic places of de-fusion}

Explanations of the current post-truth era usually conclude that social media platforms generate most of the main dysfunctions derived from misinformation. These 
explanations are often connected to echo chambers and ideological bubbles that impoverish public debate (Ball 2017; Leetaru 2017; Lewandowsky et al. 2017), the use of bots to spread disinformation and partisan content (Webb and Jirotka 2017), and trolling, a practice that polarizes citizens and extends hate speech (Hannan 2018). Under these perspectives, digital spaces seem to increase the "irrationality" of publics (Ward forthcoming), impeding civil discourse. Many authors place users in the position of retweeting and sharing the biased and false content that floods digital platforms. There is, therefore, a widely established line of thought in the academic field of media studies about the role of social media platforms as instruments that can easily be used as political tools for disseminating misleading information (Sismondo 2017) and polarizing audiences (Waisbord 2018). In most of the fact checks analyzed, digital platforms become institutions with a positive value within the civil sphere. On the one hand, private instant messaging services such as WhatsApp, a platform often used to transmit hoaxes (Salaverría et al. 2020), function as a "connection method" between the public and fact checkers so that ordinary citizens can denounce fake news and activate processes of de-fusion. On the other hand, traditional social networks such as Twitter and Facebook emerge as catalysts for these checks - that is, as powerful agents against fake news. Social media platforms are considered to be spaces that bring together the collaboration of different civil actors to detect and refute hoaxes. These civil actors can be both those affected by (false) news or well-informed citizens who have first-hand knowledge about the news stories and use social networks to dismantle them. This collaborative action between fact checkers and social media can be observed in the case of the Spanish photographer Ignacio Pereira, whose picture of Gran Vía-one of the main streets in Madrid-was doctored by the Spanish Far Right party VOX so that the street was filled with coffins. The aim of VOX's doctored image was to criticize the government's management of the coronavirus health crisis. Several users (@JCDAtrasto: "This is the real image by @ignaciopereira and I suppose that he MUST NOT be very happy") and the creator of the image himself ("This is not authorized and I will take appropriate legal action. Please RT," Ignacio Pereira on Twitter on April 6, 2020) made use of Twitter to share the original photo (without coffins) and denounce the misuse of the image.

PolitiFact's check (May 26, 2020) of Donald Trump's claim “Twitter is completely stifling FREEE SPEECH" represents another significant example that illustrates this shift of social networks from fake news generators to fact checkers. PolitiFact staff writer Bill McCarthy rates Trump's tweets attacking the social media platform as "Pants on Fire," explaining that "the statement is not accurate and makes a ridiculous claim." This fact check positioned Twitter on the side of the truth. The social network's issuing of a "get the facts" warning about the content of the Trump tweet was praised, and the platform was described in this specific case as having promoted critique and debate.

A collaborative fact-checking process is thus established, in which social media and citizens adopt a role that goes beyond the mere submission of stories to verify information. The process demonstrates that social media and citizens can play a crucial role in debunking false narratives. In these cases, collaboration between citizens and fact checkers can be observed, triggering a process of de-fusion that reconciles 
digital platforms with citizens against disinformation and, at the same time, distances political elites from citizens due to their attempts at manipulation.

On the other hand, particularly in the Spanish case, fact checkers' work regarding bottom-up hoaxes about false measures implemented by governments generated positive reactions. Citizens demanded sanctions against misinformation creators through social media. In so doing, fact checkers connected political powers with society, while opening up a secure space where citizens could obtain the facts about the crisis's impact and the real measures approved by their leaders to assist them. At the same time, fact checkers placed limits on permissible behavior to construct a healthy civil sphere. In March 2020, a hoax in the United States claimed the government would pay people $\$ 700$ a week to stay home as a measure to fight the spread of the virus. The American fact checker LeadStories confirmed that this story was false. In its report on the issue, this institution informed readers of the real measures that were being considered and the time frame in which they might be available:

US citizens may get some economic relief from Congress at some point, but that could still be a few weeks away. On March 17, 2020, the White House announced an $\$ 850$ million stimulus package, which would also include support for businesses, according to The Washington Post. Also, Republican Sen. Mitt Romney has suggested giving each American adult \$1,000, to ensure economic stability, according to CNN. However, this is merely a proposal and has not been taken up by Congress." (LeadStories, March 17, 2020)

Notably, this type of bottom-up disinformation, created and disseminated by individuals or by conspiracy-theory and/or partisan websites, represents anti-civil behaviors that are counteracted by fact checkers, which perform as agents that point out that these activities are dangerous and undesirable if the civil sphere's institutions are to function correctly and democratic life is to be vigorous (Adams 2020).

For many scholars, post-truth and fake news also reveal a progressive decline of journalism's democratic role at a time when digital media are becoming more prominent (Farkas and Schou 2020; Dahlgren 2018). This argument links misinformation to the impoverishment of legacy media's quality and credibility. "We have a bad news problem, not a fake news problem," Mikkelson (2016) points out. The "crisis in news" narrative has resulted in a gloomy de-sacralization of journalism (Alexander et al. 2016) that associates the democratic failure of journalism with citizens' increased consumption of information from partisan media of dubious quality (Ball, 2017).

Contrary to the crisis narrative, legacy media's role in the fact-checking process is highlighted by fact checkers in a particular manner. Traditional news media appear as relevant figures and are very present in the meta-discourse of fact checkers-that is, the way in which the latter legitimize their fact-checking activity. Journalistic organizations are presented as crucial trustworthy sources for verifying facts on an equal footing with respect to scientific experts or official documents. There are numerous US fact checks that show this centrality of legacy media both qualitatively and quantitatively. In the Spanish case, some fact checks reveal that some false claims that become viral on social networks are fabrications based on images and texts from legacy media. Through a careful reconstruction of the original news 
story, fact checks unmask the falsity of such manipulated content that appeared to be truthful because it included elements of journalism. For the same purpose, previous fact checks become key elements in subsequent ones. The fact checker assumes a dual role as investigative entity and creator of documentary evidence based on the original news reporting of leading journalistic organizations. On March 6, 2020, PolitiFact checked a claim in which Trump accused Obama of "not having done anything" to tackle the 2009 swine flu outbreak. This fact checker used an earlier verification ("President Obama declared H1N1 a public health emergency before anyone in the United States died" March 4, 2020) to demonstrate that Trump's claim is false. External references to legacy media are critical for the construction of this specific verifying story, but also for the general formation of fact checkers' discourse of truth. This discourse has a multi-layered dimension. Fact checkers not only determine which facts are true and which are false, but also which narratives of truth must be known and which of the many voices have enough credibility to determine the veracity of facts. The symbolic spaces of truth created by fact checkers pave the way for a process of re-fusion between trustworthy actors and publics. By referring to traditional media and to their own checks, fact-checking entities set a dividing line between two symbolic spaces (Carlson 2020): the space associated with reason, scientific knowledge, and high-quality journalism on the one hand, and the space of irrationality and distortion on the other. In the work of building such a symbolic boundary of truth, fact checkers also focus their activities on the sources of disinformation. A common strategy is to explain the lack of legitimacy of the media entity or actor that generated the misinformation. These disinformation agents are unmasked through research into their background and reputation. Based on this investigation, fact checkers help to bring together quality journalism and audiences by distinguishing media that offer truly informative content from partisan publications. This separation between the two types of media alerts the public to possible future misinformation from sources that are symbolically labeled as unreliable. On March 19, 2020, LeadStories checked a story posted on the satirical website ObamaWatcher.com. The story claimed that Obama's family escaped to a private island to protect themselves from the coronavirus. LeadStories describes the lack of legitimacy of this website and the questionable online activity of the site's owner, Christopher Blair:

The site is part of the "America's Last Line of Defense" network of satire websites run by self-professed liberal troll Christopher Blair from Maine along with a loose confederation of friends and allies. (...) Blair has been in a feud with fact-checking website Snopes for some time now and has also criticized other fact checkers in the past who labeled his work "fake news" instead of satire. In reaction to this, he has recently rebranded all his active websites and Facebook pages so they carry visible disclaimers everywhere. (LeadStories, March 19, 2020.)

On the audience side, processes of de-fusion activated by fact checkers help audiences to acquire meaningful knowledge to deal with misinformation. Fact checkers show how the creators of false and misleading stories act, thus providing powerful tools so the public can detect this type of content. References to previous checks of 
similar stories reveal the rhetoric, themes, and common mechanisms deployed when false information is created, and they define a performance of lies that is very valuable in empowering citizens' media literacy. For example, in refuting the hoax about the mobilization of the US military to take the main cities of the United States and impose martial law, LeadStories (March, 25 2020) provided a list of previously performed checks within the same thematic framework, thereby helping to position this claim as open to doubt:

Lead Stories has published stories that debunked claims that videos of the tanks on trains were a sign that the United States is preparing for martial law. (...) In another piece, Lead Stories noted an amateur video was at least seven years old and did not show the beginning of martial law being enacted in Philadelphia.

\section{Conclusion}

Our analysis has sought to interpret fact checks as units of meaning through which journalism reflexivity emerges, to a greater or lesser extent, vis-à-vis power (Alexander 2010). New fact-checking websites refer to legacy new media and actually use journalistic organizations' original reporting as sources of truth. Fact checkers' reflection on their authority is associated with professional journalism. To the extent that they first arose from civil organizations and then become professionalized via a close connection with traditional and new journalistic organizations, new fact-checking websites can be seen as an extension of professional-accountability journalism. More empirical work should be made to prove this connection. It is worth emphasizing that the analysis of the selected fact checks helps to delineate a discourse of truth that, organized around the symbolic binaries of true/false or fact/opinion, makes it possible to connect the new phenomenon of fact checking to journalism. As we mentioned in the first section of the article, most new independent fact checkers are connected to the mainstream traditional and digital journalism organizations, which call on the most prominent fact checkers to combat partisan media and disinformation.

Fact checkers allow extend the social power of journalism, which is based on journalism's democratic interpretations of individual and collective actors. Our study comes at a time when the number of fact checkers has increased dramatically as a result of the COVID-19 crisis. In addition to reflecting the journalistic and civil response to a corresponding increase in misinformation, fact checkers' remarkable growth can be taken as an indicator of journalism's energizing interpretive power for assessing the authenticity of public authorities during particularly troubled times in which citizens' collaboration and solidarity are critical for confronting major threats.

By sifting facts from inaccurate information and rating pieces of information as fake, misleading, twisted, or recontextualized, independent fact checkers mediate the connection between public authorities and audiences. We have shown how their checks and reports usually refer to "facts" and "truths" that reflect a science-driven narrative. In a context of polarizing distrust, independent fact checkers not only slow 
down viral rumors, conspiracies, trolls, or hoaxes, but their evaluations make it possible to balance public narratives with "empiricism"- "a solid dose of scepticism and scrutiny," as Pulitzer-winning science journalist Laurie Garrett puts it (The Lancet, March 11, 2020).

This interpretative power exercised by fact checkers represents one of the crucial elements of current social performances. Strategically placed between actors and audiences, independent fact checkers hold the power to facilitate re-fusion or maintain de-fusion. At best, their analysis and evaluations might foster re-fusion and become "bastions of truth" (Garret, The Lancet, March 11, 2020) from which facts are disseminated in a timely manner, so that fragmented audiences can authenticate public authorities' representations in order to decide whether or not to suspend their own interests and contribute to the common goals that governments are held accountable for.

Our research challenges theories (Kreiss 2017; Waisbord 2018) that in one way or another question the effectiveness of fact checking and journalism in a post-truth era in which opinions and emotions may have more relevance than facts in processes of interpreting reality. We have shown the way in which many checks of bottomup false claims might contribute to processes of re-fusion with governments by strengthening credible policies that are based on data and verifiable facts and by counteracting lies and unfounded criticism. However, fact checkers' interpretations might deepen de-fusion by pointing out falsehoods and inaccuracies coming from top-down claims and persuasive performances that prioritize political interest over accurate information. At the same time, processes of de-fusion based on the actions of fact checkers are usually activated when certain political parties or politicians question the credibility and legitimacy of these journalism institutions by accusing them of bias in their verification work.

Besides this decisive double game of re-fusion and de-fusion in relation to political performances, fact checkers' stories construct symbolic boundaries of truth in which legacy media organizations occupy a central place. Checks and reports usually refer to such organizations as sources of "facts" and "truths" that reflect a science-driven narrative, along with scientific experts and institutions. Similarly, fact checkers' reports both highlight social media platforms' collaborative work to confront misinformation and point out misleading claims emanating from specific individuals via the same social media. By doing so, fact checkers not only purify the new media embraced by citizens but also symbolically locate reasonable publics within the boundaries of truth.

\section{References}

Adams, K. 2020. Between trump and a hard place: Civil gatekeeping and moral equivalence in press endorsements of 2016 presidential candidates. Journalism Studies 21 (11): 1531-1550.

Alexander, J.C. 2004. Cultural pragmatics: Social performance between ritual and strategy. Sociological Theory 22 (4): 527-573.

Alexander, J.C. 2006. The civil sphere. Oxford/New York: Oxford University Press.

Alexander, J.C. 2010. The performance of politics. Obama's victory and the struggle for democratic power. Oxford/New York: Oxford University Press. 
Alexander, J.C., E.B. Breese, and M. Luengo (eds.). 2016. The crisis of journalism reconsidered: Democratic culture, professional codes, digital future. Cambridge/New York: Cambridge University Press.

Alexander, J.C., T.R. Stack, and F. Khosrokhavar (eds.). 2019. Breaching the civil order: Radicalism and the civil sphere. Cambridge: Cambridge University Press.

Aparici, R., and D. García-Marín. 2019. La posverdad. Una cartografía de los medios, las redes y la política. Barcelona: Gedisa.

Ball, J. 2017. Post-truth. How bullshit conquered the world. London: Biteback Publishing.

Bartlett, J. 2018. The people vs tech. How the internet is killing democracy (and how we save it). Londres: Penguin Random House.

Berinsky, A.J. 2015. Rumors and Health Care Reform: Experiments in Political Misinformation. British Journal of Political Science 47 (2): 241-262.

Bowman, N.D., and E. Cohen. 2020. Mental shorcuts, emotion, and social rewards: the challenge of detecting and resisting fake news. In Fake news and misinformation in the digital age, ed. M. Zimdars and K. McLeod, 223-234. Cambridge: The MIT Press.

Brennen, J.S. et al. 2020. Types, sources, and claims of covid-19 misinformation. Reuters Institute, 7 April. https://reutersinstitute.politics.ox.ac.uk/types-sources-and-claims-covid-19-misinformation

Canel, M.J. 2020. Comunicación en tiempos de coronavirus. El País, 1 April, https://elpais.com/elpai s/2020/03/31/opinion/1585667419_111894.html. Accessed 20 May 2020.

Carlson, M. 2015. Metajournalistic discourse and the meanings of journalism: Definitional control, boundary work, and legitimation. Communication Theory. https://doi.org/10.1111/comt.12088.

Carlson, M. 2020. Fake news as an informational moral panic: The symbolic deviancy of social media during the 2016 US presidential election. Information, Communication \& Society 23 (3): 374-388.

Casero-Ripollés, A. 2020. Impact of Covid-19 on the media system. Communicative and democratic consequences of news consumption during the outbreak. El profesional de la información 29 (2): e290223.

Cerezo, P. 2020. El impacto de la pandemia en la prensa, April 2020, https://www.apmadrid.es/wp-conte nt/uploads/2020/04/dosier-evoca-09-medios-y-coronavirus.pdf. Accessed 12 May 2020.

D'Ancona, M. 2017. Post-truth. The new war on truth and how to fight back. Londres: Penguin Random House.

Dahlgren, P. 2018. Media knowledge and trust: The deepening epistemic crisis of democracy. JavnostThe Public 25 (1-2): 20-27.

Downie, L., and M. Schudson. 2009. The reconstruction of American journalism. New York: Columbia University Graduate School of Journalism.

El Confidencial. 2020. El tráfico de los digitales se dispara más de un $30 \%$ en marzo por el efecto coronavirus. April 20. Retrieved from https://dircomfidencial.com/medios/el-trafico-de-los-digitales-sedispara-mas-de-un-30-en-marzo-por-el-efecto-coronavirus-20200420-1453/.

European Commission. 2019. Understanding Citizens' Vulnerabilities to Disinformation and DataDriven Propaganda, https://op.europa.eu/en/publication-detail/-/publication/3ada7fb3-7d04-11e99f05-01aa75ed71a1. Accessed 23 May 2020.

Farkas, J., and J. Schou. 2020. Post-truth, fake news and democracy. Mapping the politics of falsehood. New York and London: Routledge.

Festinger, L., H. Riecken, and S. Schachter. 1956. When prophecy fails: A social and psychological study of a modern group that predict the destruction of the world. Minneapolis: University of Minnesota Press.

Finantial Times. 2020. The US publishers hiring staff despite news media storm. https://www.ft.com/ content/9c4fcfbc-937a-4b51-94c3-444673ac156d. Accessed 29 May 2020.

Fiske, S.T., and S.E. Taylor. 2013. Social cognition: From brains to culture. Los Ángeles: SAGE.

García-Marín, D. 2020. Infodemia global Desórdenes informativos, narrativas fake y fact-checking en la crisis del Covid-19. El profesional de la información 29 (3): e290411.

Garrett, L. 2020. COVID-19: the medium is the message. March 11. https://doi.org/10.1016/S0140 $-6736(20) 30600-0$.

Graves, L. 2016. Deciding what's true: The rise of political fact-checking in American journalism. New York: Columbia University Press.

Han, B.C. 2017. La expulsión de lo distinto. Barcelona: Herder Editorial.

Hannan, J. 2018. Trolling ourselves to death? Social media and post-truth politics. European Journal of Communication 33 (2): 214-226. 
Hoffner, C., Y. Fujioka, J. Ye, and A. Ibrahim. 2009. Why we watch: Factors affecting exposure to tragic television news. Mass Communication and Society 12 (2): 193-216.

Kreiss, D. 2017. The fragmenting of the civil sphere: How partisan identity shapes the moral evaluation of candidates and epistemology. American Journal of Cultural Sociology 5: 443-459.

Kreiss, D. 2019. The Social identity of journalists. Journalism 20 (1): 27-31.

Lanier, J. 2018. Ten arguments for deleting your social media accounts right now. Londres: The Bodley Head.

Leetaru, K. 2017. Why 2017 was the year of the filter bubble, 18 December, https://www.forbes.com/ sites/kalevleetaru/2017/12/18/why-was-2017-the-year-of-the-filter-bubble/\#3431627746b8. Accessed 9 May 2020

Lewandowsky, S., J. Cook, and U.K.H. Ecker. 2017. Letting the gorilla emerge from the mist: Getting past post-truth. Journal of Applied Research in Memory and Cognition 6 (4): 418-424.

Manfredi, Juan Luis. 2015. Innovación y Periodismo: emprender en la Universidad. La Laguna: Sociedad Latina de Comunicación Social.

Mantzarlis, A. 2018. Fact-checking 101. In Journalism, fake news \& disinformation: Handbook for journalism education and training, ed. C. Ireton and J. Pose, 85-100. Unesco: París.

McIntyre, Lee. 2018. Post-truth. Cambridge: The MIT Press.

Mikkelson, D. 2016. We have a bad news problem, not a fake news problem. Snopes, 17 November, https://www.snopes.com/news/2016/11/17/we-have-a-bad-news-problem-not-a-fake-news-probl em/. Accessed 15 May 2020.

Pariser, Eli. 2011. The filter bubble: What the internet is hiding from you. London: Penguin.

Poynter. 2020. The International Fact-Checking Network, 11 August, https://www.poynter.org/ifcn/. Accessed 19 Aug 2020.

Reis, J., F. Benevenuto, P. Vaz de Melo, R. Prates, H. Kwak., and J. An. (2015) Breaking the news: first impressions matter on online news, 16 April, https://arxiv.org/abs/1503.07921. Accessed 12 May 2020.

Reuters Institute for the Study of Journalism/Oxford Internet Institute. 2020. Types, sources, and claims of COVID-19 misinformation, 7 April, https://reutersinstitute.politics.ox.ac.uk/types -sources-and-claims-covid-19-misinformation. Accessed 12 May 2020.

Salaverría, R., N. Buslón, F. López-Pan, B. León, I. López-Goñi, and M.C. Erviti. 2020. Desinformación en tiempos de pandemia: tipología de los bulos sobre la Covid-19. El profesional de la información 29 (3): e290315.

Schudson, M. 1978. Discovering the news: A social history of american newspapers. New York: Basic Books.

Sismondo, S. 2017. Post-truth? Social Studies of Science 47 (1): 3-6.

Vázquez-Herrero, J., Á. Vizoso, and X. López-García. 2019. Innovación tecnológica y comunicativa para combatir la desinformación: 135 experiencias para un cambio de rumbo. El profesional de la información 28 (3): e280301.

Waisbord, S. 2018. The elective affinity between post-truth communication and populist politics. Communication Research and Practice 4 (1): 17-34.

Ward, S.J.A. forthcoming. Democratically Engaged Journalists amid Unreasonable Publics. In News media innovation reconsidered: ethics and values in a creative reconstruction of journalism, ed. M. Luengo and S. Herrera-Damas. New York: Wiley.

Webb, H., and M. Jirotka. 2017. Nuance, societal dynamics, and responsibility in addressing misinformation in the post-truth era: Commentary on Lewandowsky, Ecker, and Cook. Journal of Applied Research in Memory and Cognition 6 (4): 414-417.

World Health Organization. 2020. Novel Coronavirus (2019-nCoV) Situation Report, 2 February.https ://www.who.int/emergencies/diseases/novel-coronavirus-2019/situation-reports. Accessed 12 May 2020.

Zillmann, D. 2009. Exemplification theory: Judging the whole by the some of its parts. Media Psychology 1 (1): 69-94.

Publisher's Note Springer Nature remains neutral with regard to jurisdictional claims in published maps and institutional affiliations. 
María Luengo is Associate Professor in the Department of Communication at Carlos III University of Madrid (Spain). Her work focuses on journalism and the civil sphere. Recent book publications include The Crisis of Journalism Reconsidered: Democratic Culture, Professional Codes, Digital Future (co-edited with Alexander and Breese, Cambridge University Press, 2016) and News Media Innovation Reconsidered (co-edited with Susana Herrera Damas, Wiley, forthcoming). Her research has appeared in European Journal of Communication, Media, Culture \& Society, Journalism, and Journalism Studies, among others.

David García-Marín Ph.D. in Sociology (specialized in Media and the Knowledge Society). Assistant Professor of Journalism at Carlos III University of Madrid, where he teaches Media Theory in the degrees of Journalism and Cultural Studies. Previously, he worked as a guest professor in several master's degree programs in digital communication, new pedagogies and transmedia journalism at UNED, where he was also the director of several courses on digital media and disinformation. He is the author of numerous articles and books focusing on current perspectives on communication and the challenge of disinformation in our society. 